\title{
Prediksi Jumlah Kunjungan Wisatawan Asing Menggunakan Algoritma Linier Regresi Multivariet
}

\author{
Muis Nanja*1 ${ }^{1}$ Hastuti Dalai ${ }^{2}$ \\ ${ }^{1,2}$ Universitas Ichsan Gorontalo; Jl.Raden Saleh No. 10, Telp. (0435) 829976, Gorontalo \\ ${ }^{3}$ Jurusan Teknik Informatika, FIKOM UNISAN, Gorontalo \\ e-mail: *1'muisnanja@unisan.ac.id, ${ }^{2}$ hastutidalai@unisan.ac.id
}

\begin{abstract}
Abstrak
Pariwisata merupakan salah satu komponen yang turut berpartisipasi dalam Anggaran Pendapatan Daerah (APBD).[1] Meningkat atau menurunnya jumlah kunjungan wisatawan asing tentunya memberikan efek tertentu bagi pariwisata Gorontalo, peningkatan jumlah pengunjug tentunya berimbas positif terhadap pemerintahan Gorontalo khususnya dibidang kepriwisataan sebaliknya penurunan jumlah kunjungan tentunya berimbas negative yang ditimbulkan bagi kepariwisataan. Berfluktuatifnya jumlah kunjungan wisatawan asing telah menjadi permasalahan tersendiri bagi dinas pariwisata atau pemerintahan dikarenakan ditmukannya suatu kesulitan untuk memperkirakan berapa jumlah kunjungan dimasa yang akan datang. Melihat fenomena ketidak stabilannya (fluktuatifnya) jumlah kunjungan wisatawan asing telah menjadi bahan utama peneliti untuk melakukan analisa terhadap pola kunjungan wiasatawan asing untuk dilakukan prediksi atau perkiraan jumlah kunjungan dengan menggunakan Algoritma Linier Regresi Berganda (Multivariet) berbasis Forward selection, sehingga pemerintah atau dinas pariwisata dapat melakukan antisipasi berdasarkan hasil prediksi yang telah diperoleh. Berdasarkan hasil pengujian metode diperoleh nilai Root Mean Square Error (RMSE) yaitu, Regresi Multivariet 2660,89, Regresi Multivariet Forward Selection 556,49, Regresi Multivariet Backward Selection 2377,44. Sehingga dapat disimpulkan bahwa metode yang paling baik digunakan untuk melakukan prediksi yaitu Regresi Multifariet Forward Selection.
\end{abstract}

Kata kunci: Kunjungan Wisatawan, Prediksi,Regresi multivariet, fitur seleksi

\begin{abstract}
Tourism is one component that participates in the Regional Revenue Budget (APBD).[1] An increase or decrease in the number of foreign tourist visits certainly has a certain effect on Gorontalo tourism, an increase in the number of visitors certainly has a positive impact on the Gorontalo government, especially in the field of tourism. The fluctuating number of foreign tourist visits has become a separate problem for the tourism office or government due to the difficulty of estimating the number of visits in the future. Seeing the phenomenon of instability (fluctuating) the number of foreign tourist visits has become the main ingredient for researchers to analyze the pattern of foreign tourist visits to predict or estimate the number of visits by using the Multiple Linear Regression Algorithm (Multivariet) based on Forward selection, so that the government or tourism office can anticipate based on the prediction results that have been obtained. Based on the results of the method test, the Root Mean Square Error (RMSE) value was obtained, namely, Multivariet Regression 2660.89, Forward Selection Multivariet Regression 556.49, Backward Selection Multivariet Regression 2377.44. So it can be concluded that the best method used to make predictions is Multifariet Forward Selection Regression.
\end{abstract}

Keywords: Tourist Visits, Predictions, Multivariate Regressi, Feature Selection 


\section{PENDAHULUAN}

Pariwisata merupakan salah satu sektor yang yang turut membantu preekonomian Negera secara signifikan, pariwisata memberikan sumbangsi untuk kemajuan ekonomi Negara karena industri tersebut mampu memberikan dan meningkatkan lapangan kerja, taraf hidup serta mampu memicu tumbuhnya produksi lain yang berhubungan dengan wisatawan.[2] Pariwisata memberikan dampak positif bagi negara-negara yang sedang berkembang. Dampak positif itu ditandai dengan pertumbuhan ekonomi yang cukup signifikan, seperti meningkatkan pendapatan pemerintah yang tentunya dapat dimanfaatkan untuk meningkatkan dan memperkenalkan suatu Negara.[3] Menurut Ekanayake,[1] Pemerintah negara-negara berkembang harus fokus pada kebijakan ekonomi untuk mempromosikan pariwisata sebagai sumber potensi pertumbuhan ekonomi.Beraneka ragamnya obyek wisata yang terdapat di provinsi Gorontalo berdampak pada semakin meningkatnya jumlah wisatawan yang datang ke Provinsi Gorontalo.

perkembangan industri pariwisata[4], maka perlu diperhatikan oleh dinas pariwisata dalam mengetahui kunjungan wisatawan yang akan datang di provinsi Gorontalo khususnya Wisatawan Manca Negara (Wisman) karena dinas pariwisata dihadapkan dengan masalah yakni berflutuatifnya jumlah pengunjung wisatawan asing sehingga sulitnya pemerintah atau dinas pariwisata untuk mengetahui kunjungan wisatawan asing yang datang di provinsi Gorontalo, karena jumlah pengunjung setiap bulannya selalu berubah-ubah atau tidak dapat diprediksi dan kondisi tersebut juga memberikan kesulitan bagi pemerintah atau dinas pariwisata untuk mengantisipasi kemungkanian-kemungkinan yang akan terjadi perihal jumlah kunjungan wisatawan asing. [5]

Melihat dari permasalahan yang ada yaitu tidak menentunya jumlah pengunjung wisatawan asing yang datang ke Gorontalo, maka dibutuhkan suatu komputerisasi yang dapat membantu pihak pemerintah dalam memprediksi kunjungan wisatawan Asing yang berkunjung di Provinsi Gorontalo, adapun metode yang digunakan dalam penelitian ini adalah metode Linier Regresi Multivariet. Metode ini merupakan salah satu metode yang sangat baik dalam pengolahan data time series atau data musiman.

Kualitas dari metode tersebut telah dibuktikan oleh beberapa peneliti sebelumya seperti penelitian yang dilakukan oleh Edriani lestari dkk dengan judul penelitiannya yaitu Pemilihan Model Regresi Linier Multivariat Terbaik Dengan Kriteria Mean Square Error Dan Akaike's Information Criterion dengan hasil yang diperoleh yaitu pengujian antar variabel respon memiliki hubungan yang cukup kuat dengan nilai korelasi sebesar 0,425 ,[6] penelitian yang dilakukan oleh Indri puspitasari dkk dengan penelitiannya pemodelan Regresi Linier Multivariat dengan metode pemilihan model Forward Selection dan all Possible Subset Selection pada jumlah kematian bayi dan indeks pembangunan manusia (IPM), hasil penelitian yang diperoleh yaitu model Linier Regresi terbaik diperoleh dari Forward Selection,[7] penelitian yang dilakukan oleh Novelysa Samosir dkk dengan judulnya analisa metode Backward dan metode Forward untuk menentukan persamaan Regresi Linier berganda nilai Persentase yang didapatkan dengan Backward dan Forward sebesar 88,07 \%.[8] berdasarkan dari permasalahan yang dikemukakan sebelumnya maka peneliti akan melakukan pemnelitian yaitu prediski jumlah kunjungan wisata asing menggunakan Algoritma Linier Regresi Multivariet disamping itu peneliti juga akan menggunakan fiture seleksi untuk mendapatkan model terbaik untuk melakukan prediksi.dari hasil penelitian ini diharapkan dapat memberikan sumbangsi bagi dalam hal pengembangan tempat wisata, sehingga dapat menarik kunjungan wisatawan manca Negara dan wisatawan nusantara, untuk berkunjung ke Provinsi Gorontalo. Tujuan dari penelitian ini adalah diaharapkan dapat membantu pihak terkait (pemerintah atau dinas pariwisata) agar dapat mengambil kebijakan perihal dari hasil penelitian yang diperoleh guna untuk mengembangkan atau mingktakatkan sector pariwisata Provinsi Gorontalo.

Muis Nanja, et., al [Prediksi Jumlah Kunjungan Wisatawan Asing Menggunakan Algoritma Linier Regresi Multivariet] 


\section{METODE PENELITIAN}

\subsection{Metode}

Metode Penelitian pada tahapan ini untuk menjawab pertanyaan penelitian, serta untuk mencapai tujuan penelitian.

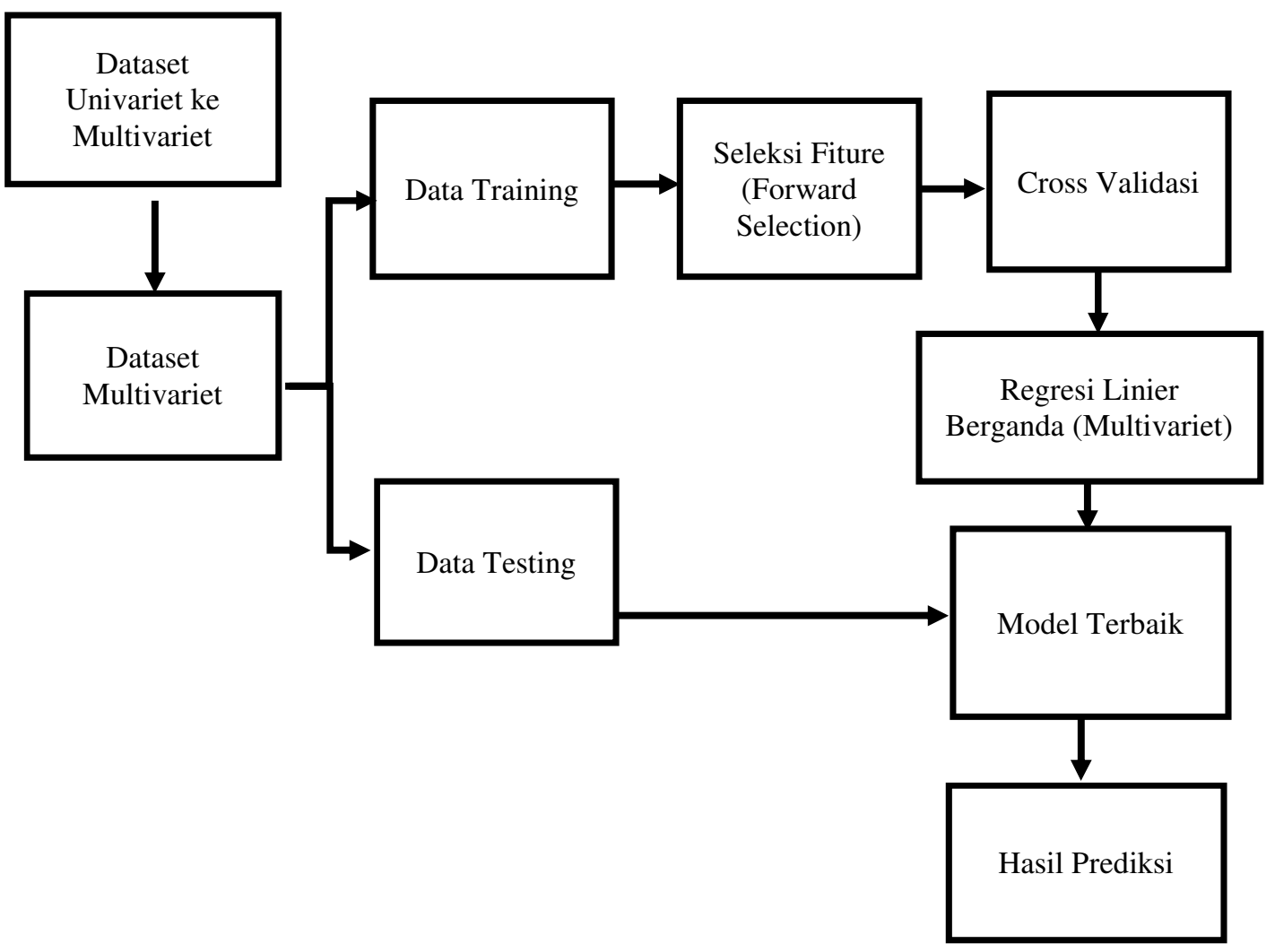

Gambar 1. Metode yang Diusulkan

Sebelum melakukan pengujian model atau melakukan eksperiment peneliti melakukan prapengolahan data sebagai tahap pertama, hal ini dilakukan karena data yang diperoleh merupakan data time series dengan satu variabel (univariet) untuk itu peneliti mengolah menjadai data lebih dari satu variabel atau 10 variabel (multivariet) dengan teknik pengubahan data dari univariet ke multivariet. Tahap kedua peneliti melakukan pengujian model Linier Regresi Multivariet dengan memasukan atribut atau variabel satu persatu sampai variabel bebas habis diinput dengan melihat hasil masing-masing pada hasil root means square error (RMSE) yang dihasilkan dan melihat nilai RMSE yang paling kecil. Tahap ketiga melakukan pengujian model Linier Regresi Multivariet berbasis forward selection dengan cara memasukkan atribut satu persatu kedalam model dan melihat hasil pengolahan datanya berupa nilai RMSE. Tahap keempat melakukan pengujian model Linier Regresi Multivariet berbasis backward elimination dengan melakukan pengimputan atribut sama dengan pada tahap ketiga. 


\subsection{Pengolahan Data}

Sumber data pada penelitian ini diambil dari Dinas Pariwisata Provinsi Gorontalo. Data yang diperoleh berupa data tahunan time series univariat, berupa data jumlah kunjungan wisatawan asing yaitu data set dari tahun 2002-2018.

Time series multivariate memodelkan peubah-peubah yang berkorelasi dan tercatat dari waktu ke waktu. Peubah tersebut dinotasikan dalam gambar dan tabel sebagai berikut:

\section{Time series data for training}

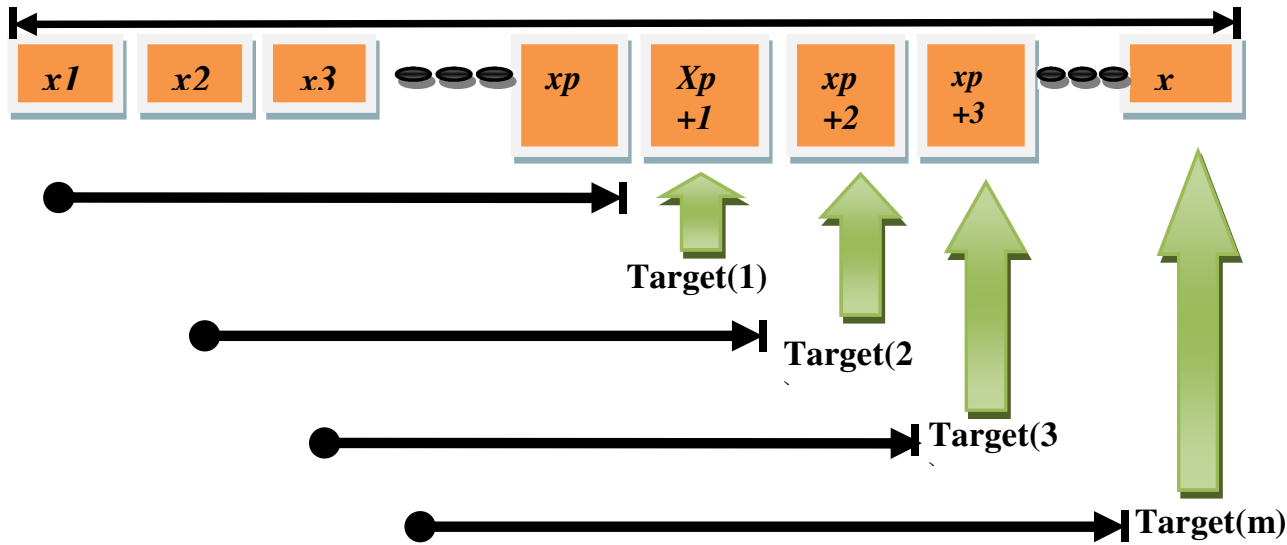

Gambar 1. Skema Data Univariet ke Multivariet [9]

Tabel 1. Data univariet time series untuk Algoritma Regresi Linier Multivariet [9]

\begin{tabular}{|llc|}
\hline Pattern & Input lag & Output/ \\
Target & & \\
\hline 1 & $x 1, x 2, x 3, x 4, \ldots, x p$ & $x p+1$ \\
2 & $x 2, x 3, x 4, x 5, \ldots, x p+1$ & $x p+2$ \\
3 & $x 3, x 4, x 5, x 6, \ldots, x p+2$ & $x p+3$ \\
$\ldots$ & $\ldots$ & $\ldots \ldots$ \\
$m-p$ & $x m-p, x m-p+1, x m-p+2, \ldots, x m-1$ & $x m$ \\
\hline
\end{tabular}

Berdasarkan Tabel. 1 merupakan pola yang bisa digunakan dalam mengubah data univariet menjadi multivariet, pola atau modelnya sebagai berikut:

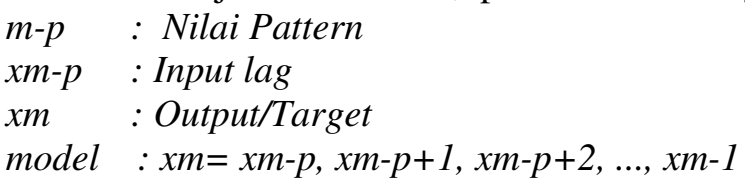

Tabel 2. Data Univariat Kunjungan Wisatawan Asing

\begin{tabular}{|c|c|}
\hline Tahun & $\begin{array}{c}\text { Jumlah } \\
\text { WISMAN }\end{array}$ \\
\hline 2002 & 282 \\
\hline 2003 & 333 \\
\hline 2004 & 551 \\
\hline 2005 & 656 \\
\hline
\end{tabular}


Jatisi

ISSN 2407-4322

Vol. 8, No. 4, Desember 2021, Hal. 1844-1853

E- ISSN 2503-2933

1848

\begin{tabular}{|c|c|}
\hline 2006 & 937 \\
\hline 2007 & 31379 \\
\hline 2008 & 19471 \\
\hline 2009 & 1817 \\
\hline Tahun & $\begin{array}{c}\text { Jumlah } \\
\text { WISMAN }\end{array}$ \\
\hline 2010 & 455 \\
\hline 2011 & 1989 \\
\hline 2012 & 2060 \\
\hline 2013 & 3238 \\
\hline 2014 & 4092 \\
\hline 2015 & 3634 \\
\hline 2016 & 5923 \\
\hline 2017 & 6240 \\
\hline 2018 & 8532 \\
\hline
\end{tabular}

Dinas pariwisata provinsi Gorontalo 2018[10]

Dalam pengolahan dari data univariat ke dalam bentuk multivariat dapat digunakan model berikut:

Tabel 3. Data Multivariat 10 Periode Inputan

\begin{tabular}{|c|c|c|c|c|c|c|c|c|c|c|}
\hline $\boldsymbol{x} 1$ & $\boldsymbol{x} \mathbf{2}$ & $\boldsymbol{x} \mathbf{3}$ & $\boldsymbol{x} \mathbf{4}$ & $\boldsymbol{x} \mathbf{5}$ & $\boldsymbol{x 6}$ & $\boldsymbol{x} 7$ & $\boldsymbol{x} 8$ & $\boldsymbol{x} \mathbf{9}$ & $\boldsymbol{x} \mathbf{1 0}$ & $\boldsymbol{y}$ \\
\hline 282 & 333 & 551 & 656 & 937 & 31379 & 19471 & 1817 & 455 & 1989 & 2060 \\
\hline 333 & 551 & 656 & 937 & 31379 & 19471 & 1817 & 455 & 1989 & 2060 & 3238 \\
\hline 551 & 656 & 937 & 31379 & 19471 & 1817 & 455 & 1989 & 2060 & 3238 & 4092 \\
\hline 656 & 937 & 31379 & 19471 & 1817 & 455 & 1989 & 2060 & 3238 & 4092 & 3634 \\
\hline 937 & 31379 & 19471 & 1817 & 455 & 1989 & 2060 & 3238 & 4092 & 3634 & 5923 \\
\hline 31379 & 19471 & 1817 & 455 & 1989 & 2060 & 3238 & 4092 & 3634 & 5923 & 6240 \\
\hline 19471 & 1817 & 455 & 1989 & 2060 & 3238 & 4092 & 3634 & 5923 & 6240 & 8532 \\
\hline
\end{tabular}

\subsection{Parameter Linier Regresi Multivariet}

Berdasarkan dari tahapan-tahapannya, pada tahap ini peneliti akan melakukan uji coba untuk menentukan model yang terbaik antara data 1 variabel priode sampai dengan 10 variabel denagan mengujikan pada 10 fold cross validation.

Tabel 4. Percobaan Pemilihan Model Regresi Linier Multivariet Berbasis Forward Selection Untuk Data

Kunjungan Wisatawan Asing

\begin{tabular}{|c|c|c|}
\hline $\begin{array}{c}\text { Nilai Variabel } \\
\text { Periode }\end{array}$ & $\begin{array}{c}\text { Number of } \\
\text { Validation }\end{array}$ & RMSE \\
\hline 1 & 10 & 7064.393 \\
\hline 2 & 10 & 7745.180 \\
\hline 3 & 10 & 5877.327 \\
\hline
\end{tabular}

Muis Nanja, et., al [Prediksi Jumlah Kunjungan Wisatawan Asing Menggunakan Algoritma Linier Regresi 


\begin{tabular}{|l|l|l|}
4 & 10 & 7871.912 \\
\hline 5 & 10 & 27948.180 \\
\hline 6 & 10 & 8362.086 \\
\hline 7 & 10 & 9026.426 \\
\hline 8 & 10 & 2660.899 \\
\hline 9 & 10 & 147491.942 \\
\hline 10 & 10 & 11127.723 \\
\hline
\end{tabular}

Berdasarkan pada Tabel 4 yaitu percobaan penentuan model dengan 1 periode sapai dengan 10 periode untuk data jumlah kunjungan wisatawan asing dengan menggunakan cross validation 10 yang dipilih berdasarkan nilai root mean square error (RMSE) terkecil. Dari hasil percobaan yang dilakukan dengan algoritma Regresi Linier Multivariet, maka diperoleh error terkecil senilai 2660.899 , yaitu pada nialai variabel periode 8 .

Tabel 5. Percobaan Pemilihan Model Regresi Linier Multivariet Berbasis Forward Selection Untuk Data

Kunjungan Wisatawan Asing

\begin{tabular}{|c|c|l|}
\hline $\begin{array}{c}\text { Nilai Variabel } \\
\text { Periode }\end{array}$ & $\begin{array}{c}\text { Number of } \\
\text { Validation }\end{array}$ & $\begin{array}{c}\text { RMSE Forward } \\
\text { Selection }\end{array}$ \\
\hline 1 & 10 & 7064.393 \\
\hline 2 & 10 & 7147.93 \\
\hline 3 & 10 & 5719.722 \\
\hline 4 & 10 & 6267.965 \\
\hline 5 & 10 & 6195.114 \\
\hline 6 & 10 & 3935.604 \\
\hline 7 & 10 & 2132.222 \\
\hline 8 & 10 & 1498.359 \\
\hline 9 & 10 & 936.453 \\
\hline 10 & 10 & 556.491 \\
\hline
\end{tabular}

Berdasarkan pada Tabel 5 yaitu percobaan penentuan model dengan 1 periode sapai dengan 10 periode untuk data jumlah kunjungan wisatawan asing dengan menggunakan cross validation 10 yang dipilih berdasarkan nilai root mean square error (RMSE) terkecil. Dari hasil percobaan yang dilakukan dengan algoritma Regresi Linier Multivariet berbasis Forward Selection, maka diperoleh error terkecil senilai 556,491, pada niali variabel 10 dengan $\mathrm{x} 1, \mathrm{x} 3, \mathrm{x} 8$ dan $\mathrm{x} 9$ merupakan variabel yang signivikan.

Tabel 6. Percobaan Pemilihan Model Regresi Linier Multivariet Berbasis Backward Elimination Untuk Data

Kunjungan Wisatawan Asing

\begin{tabular}{|c|c|c|}
\hline $\begin{array}{c}\text { Nilai Variabel } \\
\text { Periode }\end{array}$ & $\begin{array}{c}\text { Number of } \\
\text { Validation }\end{array}$ & $\begin{array}{c}\text { RMSE Bacward } \\
\text { Elimination }\end{array}$ \\
\hline 1 & 10 & 7064.393 \\
\hline 2 & 10 & 6980.835 \\
\hline
\end{tabular}

Muis Nanja, et., al [Prediksi Jumlah Kunjungan Wisatawan Asing Menggunakan Algoritma Linier Regresi 


\begin{tabular}{|c|l|l|}
\hline 3 & 10 & 5719.722 \\
\hline 4 & 10 & 6267.965 \\
\hline 5 & 10 & 6584.000 \\
\hline 6 & 10 & 3016.219 \\
\hline 7 & 10 & 4647.062 \\
\hline 8 & 10 & 2660.899 \\
\hline 9 & 10 & 2426.610 \\
\hline 10 & 10 & 2377.449 \\
\hline
\end{tabular}

Berdasarkan pada Tabel 6 yaitu percobaan penentuan model dengan 1 sampai dengan 10 periode untuk jumlah kunjungan wisatawan asing dengan menggunakan cross validation 10 yang dipilih berdasarkan nilai root mean square error (RMSE) terkecil. Dari hasil percobaan yang dilakukan dengan algoritma Regresi Linier Multivariet berbasis Backward Elimination, maka diperoleh error terkecil senilai 2377.449, pada niali variabel 10 dengan $\mathrm{x} 1, \mathrm{x} 2, \mathrm{x} 4, \mathrm{x} 5, \mathrm{x} 7, \mathrm{x} 8, \mathrm{x} 9$ dan $\mathrm{x} 10$ merupakan variabel yang signivikan.

Tabel 7. Perbandingan Hasil Percobaan Metode Model Regresi Linier Multivariet Dengan Fiture Seleksi dan Tanpa Fitur Seleksi.

\begin{tabular}{|c|l|l|l|}
\hline $\begin{array}{c}\text { Nilai Variabel } \\
\text { Periode }\end{array}$ & \multicolumn{1}{|c|}{ RMSE } & $\begin{array}{c}\text { RMSE Forward } \\
\text { Selection }\end{array}$ & $\begin{array}{c}\text { RMSE Bacward } \\
\text { Elimination }\end{array}$ \\
\hline 1 & 7064.393 & 7064.393 & 7064.393 \\
\hline 2 & 7745.180 & 7147.93 & 6980.835 \\
\hline 3 & 5877.327 & 5719.722 & 5719.722 \\
\hline 4 & 7871.912 & 6267.965 & 6267.965 \\
\hline 5 & 27948.180 & 6195.114 & 6584.000 \\
\hline 6 & 8362.086 & 3935.604 & 3016.219 \\
\hline 7 & 9026.426 & 2132.222 & 4647.062 \\
\hline 8 & 2660.899 & 1498.359 & 2660.899 \\
\hline 9 & 147491.942 & 936.453 & 2426.610 \\
\hline 10 & 11127.723 & 556.491 & 2377.449 \\
\hline
\end{tabular}

Berdasarkan Tabel 7 yang merupakan tabel perbandingan model terbaik untuk data jumlah Kunjungan wisatwan asing, antara Regresi Linier Multivariet, Regresi Linier Multivariet berbasis Forward Selection dan Regresi Linier Multivariet berbasis Backward Elimination menunjukkan bahwa model yang paling baik terdapat pada nilai variabel periode 10 dengan menggunakan forward selection yaitu nilai $r m s$-nya sebesar 556.491 .

\subsection{Evaluasi}

Model yang dipilih berdasarkan nilai root mean square error (RMSE) terkecil yang diperoleh. Berdasarkan hasil percobaan yang dilakukan, maka ditentukan model yang akan digunakan untuk melakukan prediksi jumlah kunjungan wisatawan asing yaitu model dengan tingkat error terkecil yang dapat dilihat pada tabel berikut: 
Tabel 8. Hasil Pengujian Metode Regresi Multivariet

\begin{tabular}{|l|c|}
\hline \multicolumn{1}{|c|}{ Algoritma } & RMSE \\
\hline Regresi Multivariet & 2660.89 \\
\hline Regresi Multivariet Forward & 556.49 \\
\hline Regresi Multivariet Bacward & 2377.44 \\
\hline
\end{tabular}

Berdasarkan dari hasil pengujian metode yang telah dilakukan seperti pada table 3 . Maka dapat disimpulkan bahwa metode yang memiliki nilai error terkecil (RMSE) adalah metode Linier Regresi Multivariet Berbasis Forward Selection.

\subsection{Implementasi}

Pada tahap ini yaitu tahap pengaplikasian model terbaik yang telah didapatkan dari hasil eksperiment yang telah peneliti lakukan yaitu mengimplementasikan dataset sebanyak 2 record untuk prediksi jumlah kunjungan wisatawan asing selama 2 tahun kedepan, hasil prediksi dapat dilihat pada gambar grafik berikut:

Tabel 9. Hasil Prediksi Jumlah

Kunjungan Wisatawan Asing

\begin{tabular}{|c|c|c|}
\hline No & Tahun & Jumlah WISMAN \\
\hline 1 & 2016 & 5923 \\
\hline 2 & 2017 & 6240 \\
\hline 3 & 2018 & 8532 \\
\hline 4 & 2019 & 19279 \\
\hline 5 & 2020 & 16559 \\
\hline
\end{tabular}

\section{HASIL DAN PEMBAHASAN}

Berdasarkan dari penerapan model terbaik untuk melakukan prediksi jumlah kunjungan wisatawan asing untuk 2 tahun kedepan 2019 dan 2020 diperoleh nilai prediksi sebagai berikut:

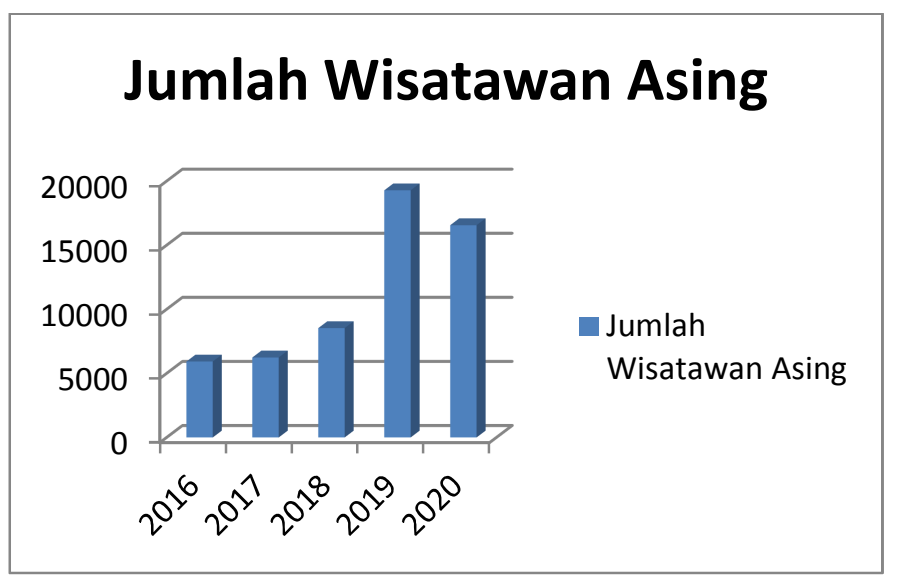

Gambar 2. Hasil Prediksi Jumlah Kunjungan Wisatawan Asing 
Tabel 8. Hasil Prediksi 2 Tahun Mendatang

\begin{tabular}{|c|c|c|}
\hline No & Tahun & $\begin{array}{c}\text { Jumlah } \\
\text { WISMAN }\end{array}$ \\
\hline 1 & 2016 & 5923 \\
\hline 2 & 2017 & 6240 \\
\hline 3 & 2018 & 8532 \\
\hline 4 & 2019 & 19279 \\
\hline 5 & 2020 & 16559 \\
\hline
\end{tabular}

\section{KESIMPULAN}

Berdasarkan dari hasil pengujian yang telah dilakukan, dapat disimpulkan bahwa metode yang memiliki nilai error terkecil adalah metode Linier Regresi Multivariet Berbasis forward selection dengan nilai RMSE yang diperoleh sebesar 556,49 lebih kecil dari perolehan tingkat error dari metode Linier Regresi Multivariet sebesar 2660,89, Linier Regresi Multivariet Berbasis Backward Elimination sebesar 2377, sehingga Linier Regresi Multivariet berbasis forward Selection adalah model yang terbaik.

\section{SARAN}

Penelitian ini perlu dikembangan lebih lanjut guna memperoleh nilai error lebih kecil agar peneliti berikutnya dapat melakukan perbandingan dengan metode lainnya.

\section{UCAPAN TERIMA KASIH}

Penulis mengucapkan terima kasih kepada LLDikti IX yang telah memberi dukungan financial terhadap penelitian ini.

\section{DAFTAR PUSTAKA}

[1] E. M. Ekanayake and A. E. Long, "Tourism Development and Economic Growth in Developing Countries,” No. September, 2014.

[2] N. L. G. A. Pertiwi, 2014. "Pengaruh Kunjungan Wisatawan, Retribusi Obyek Wisata dan Phr Terhadap Pad Kabupaten Gianyar,” E-Jurnal Ekon. Pembang. Univ. Udayana, Vol. 3, No. 3, pp. 115-123,

[3] N. Palladino, 1981. "Regulatory Reform," Chem. and Engineering News, Vol. 59, No. 50, p. 5 ,

[4] A. Maulana et al., 2016. "Sektor Pariwisata Di Indonesia The Influence of International and Domestic Tourist Addin Maulana Peneliti pada Asisten Deputi Penelitian dan Pengembangan Kebijakan Kepariwisataan, Kementerian Pariwisata Gd. Sapta Pesona, Jl. Medan Merdeka Barat No . 1," pp. 119-143, 
[5] Badan Pusat Statistik, 2018, Gorontalo Dalam Angka 2018.

[6] E. Lestari, R. Goejantoro, and M. N. Hayati, 2016. "Pemilihan Model Regresi Linier Multivariat Terbaik Dengan Kriteria Mean Square Error dan Akaike's Information Criterion," pp. 3-7,

[7] J. Kematian, B. Dan, I. Pembangunan, and M. Ipm, 2015 “1 , 2 , 3,” Vol. 4, No. 2014, pp. 907-916,.

[8] N. Samosir, P. Siagian, and P. Bangun, 2014, "Analisa Metode Backward dan Metode Forward Untuk Menentukan,” Vol. 2, No. 4, pp. 345-360.

[9] C. Eswaran and R. Logeswaran, 2011. "Improved Adaptive Neuro-Fuzzy Inference System for HIV / AIDS Time Series Prediction,” pp. 1-13.

[10] Badan Pusat Statistik, 2018, Gorontalo Dalam Angka 2018. 